\title{
Prolonged hypoxia augments L-citrulline transport by System $A$ in the newborn piglet pulmonary circulation
}

\author{
Candice D. Fike 1,2*, Marta Sidoryk-Wegrzynowicz ${ }^{1,2}$, Michael Aschner, 2,3,4, \\ Marshall Summar ${ }^{5}$, Lawrence S. Prince, Gary Cunningham ${ }^{5}$, Mark Kaplowitz ${ }^{1,2}$, \\ Yongmei Zhang 1,2, and Judy L. Aschner 1,2,3,4
}

\begin{abstract}
1Department of Pediatrics, Vanderbilt University School of Medicine, Vanderbilt University Medical Center, 2215 B Garland Ave., 1125 MRB IV/Light Hall, Nashville, TN 37232-0656, USA; ${ }^{2}$ Monroe Carell Jr. Children's Hospital at Vanderbilt, Nashville, TN, USA; ${ }^{3}$ Vanderbilt Center for Molecular Toxicology, Nashville, TN, USA; ${ }^{4}$ Vanderbilt Kennedy Center for Research on Human Development, Nashville, TN, USA; and ${ }^{5}$ Division of Genetics and Metabolism, Children's National Medical Center, Washington, DC, USA
\end{abstract}

Received 11 November 2011; revised 9 May 2012; accepted 31 May 2012; online publish-ahead-of-print 6 June 2012

Time for primary review: 21 days

Aims

Pulmonary arterial endothelial cells (PAECs) express the enzymes needed for generation of L-arginine from intracellular L-citrulline but do not express the enzymes needed for de novo L-citrulline synthesis. Hence, L-citrulline levels in PAECs are dependent on L-citrulline transport. Once generated, L-arginine can be converted to L-citrulline and nitric oxide (NO) by the enzyme NO synthase. We sought to determine whether hypoxia, a condition aetiologically linked to pulmonary hypertension, alters the transport of L-citrulline and the expression of the sodium-coupled neutral amino acid transporters (SNATs) in PAECs from newborn piglets.

Methods and results

Conclusion

Keywords
PAECs isolated from newborn piglets were cultured under normoxic and hypoxic conditions and used to measure SNAT1, 2, 3, and 5 protein expression and ${ }^{14} \mathrm{C}$-L-citrulline uptake. SNAT1 protein expression was increased, while SNAT2, SNAT3, and SNAT5 expression was unaltered in hypoxic PAECs. ${ }^{14} \mathrm{C}$-L-citrulline uptake was increased in hypoxic PAECs. Studies with inhibitors of System A (SNAT1/2) and System N (SNAT3/5) revealed that the increased ${ }^{14} \mathrm{C}$-L-citrulline uptake was largely due to System A-mediated transport. Additional studies were performed to evaluate SNAT protein expression and L-citrulline levels in lungs of piglets with chronic hypoxia-induced pulmonary hypertension and comparable age controls. Lungs from piglets raised in chronic hypoxia exhibited greater SNAT1 expression and higher L-citrulline levels than lungs from controls.

Increased SNAT1 expression and the concomitant enhanced ability to transport L-citrulline in PAECs could represent an important regulatory mechanism to counteract $\mathrm{NO}$ signalling impairments known to occur during the development of chronic hypoxia-induced pulmonary hypertension in newborns.

Pulmonary hypertension • Sodium-coupled neutral amino acid transporters • Nitric oxide

\section{Introduction}

L-Citrulline provides an intracellular source for L-arginine via a biosynthetic pathway involving the enzymes argininosuccinate synthetase (ASS) and argininosuccinate lyase (ASL). ${ }^{1}$ L-Arginine is the substrate for nitric oxide synthase (NOS), which generates nitric oxide (NO) and citrulline; together these two pathways form a mechanism for citrulline recycling ${ }^{1}$ (Figure 1). The regulation of $\mathrm{NO}$ biosynthesis via intracellular metabolism of L-citrulline is poorly understood and may represent a novel target for therapeutic intervention for conditions associated with $\mathrm{NO}$ dysfunction, such as some forms of neonatal pulmonary hypertension. ${ }^{2-4}$ While pulmonary arterial endothelial cells (PAECs) express ASS and ASL, they do not express the enzymes needed for de novo synthesis of L-citrulline. ${ }^{5}$ Thus, intracellular citrulline concentrations depend, at least in part, on the uptake of circulating blood-borne L-citrulline produced primarily in the intestines. ${ }^{6,7}$ Remarkably, little is known about the neutral amino acid transporters responsible for L-citrulline transport into PAECs. ${ }^{8}$

The $\mathrm{Na}^{+}$-dependent neutral amino acid transporters (SNATs) are one of the major systems responsible for neutral amino acid transport 


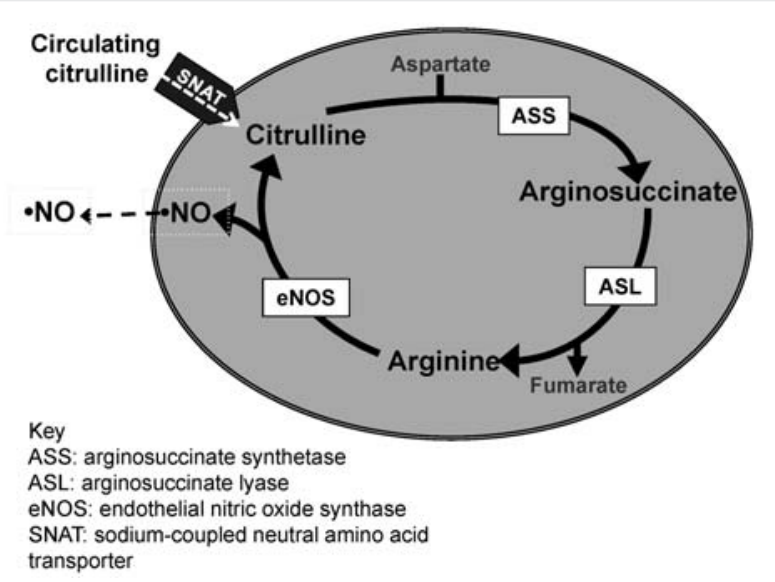

Figure I Schematic of the citrulline recycling pathway in endothelial cells. Note that there are currently five known SNAT proteins (SNATs 1-5).

in mammalian cells. ${ }^{9-11}$ SNATs are expressed in most cell types and are categorized as System A or System N, dependent in part on their functional properties. Recently, the SLC38 gene family of transporters were identified, renamed SNATs 1-5, and subdivided based on the similarity of their transport properties to System A or System N. ${ }^{12}$ Many factors, including hormones, growth factors, and hyperosmotic stress, have been associated with changes in the activities and expression of SNAT proteins. ${ }^{9-15}$ However, to date, little is known about the impact on SNAT expression or L-citrulline transport in PAECs from conditions such as hypoxia that are associated with the development of pulmonary hypertension. ${ }^{16}$

Newborn piglets exposed to prolonged hypoxia develop pulmonary hypertension. ${ }^{17}$ The primary goal of this study was to determine whether prolonged hypoxia alters expression of SNAT proteins and L-citrulline uptake by PAECs isolated from newborn piglets. We also performed studies to determine whether SNAT expression and citrulline levels are altered in lungs of piglets exposed to 3 or 10 days of hypoxia.

\section{Methods}

\subsection{Animals: in vivo hypoxia model}

York-Landrace mixed breed piglets were obtained from the vendor on day of life $2(n=14)$ and raised in a normobaric hypoxic environment until either day of life 5 ( 3 days of hypoxia; $n=7$ ) or day of life 12 (10 days of hypoxia; $n=7$ ) following our previously described methods. ${ }^{2,17}$ $\mathrm{O}_{2}$ content was regulated at $10-12 \% \mathrm{O}_{2} . \mathrm{CO}_{2}$ was absorbed with soda lime, and $\mathrm{PCO}_{2}$ was maintained at 3-6 Torr. The chamber was opened twice each day to clean the chamber and to weigh the animals. The piglets were fed artificial sow milk ad libitum. Normoxic, age-matched control animals were either 5 days old $(n=7)$ or 12 days old $(n=7)$ when obtained from the vendor and studied on the day of arrival, i.e. at the same post-natal ages as the hypoxic piglets.

To obtain the tissue used in these experiments, 5-day-old or 12-day-old piglets were pre-anaesthetized with ketamine $(30 \mathrm{mg} / \mathrm{kg} \mathrm{im})$ and acepromazine $(2 \mathrm{mg} / \mathrm{kg} \mathrm{im})$ and then anaesthetized with pentobarbital sodium $(10-20 \mathrm{mg} / \mathrm{kg}$ iv). All animals were given heparin $(1000 \mathrm{IU} / \mathrm{kg}$ iv) and then exsanguinated. The depth of anaesthesia prior to exsanguination was monitored by assessing consciousness and response to painful stimuli. The thorax was opened and the lungs were removed. The investigation conformed with the Guide for the Care and Use of Laboratory Animals published by the US National Institutes of Health (NIH Publication No. 85-23) and was approved by the Institutional Animal Care and Use Committee of Vanderbilt University Medical Center, which is fully accredited by the Association for Assessment and Accreditation of Laboratory Animal Use.

\subsection{Whole lung tissue and pulmonary artery isolation}

Distal pieces of whole lung and pulmonary arteries $>1 \mathrm{~mm}$ were dissected from both age-matched control and hypoxic piglet groups, frozen in liquid nitrogen, and stored at $-80^{\circ} \mathrm{C}$ until use.

\subsection{PAEC isolation}

The main pulmonary artery was isolated from the lungs of 5-day-old piglets $(n=5)$ and used to obtain PAECs following modified methods. ${ }^{18}$ Each pulmonary artery was flushed with PBS, then filled with $0.25 \%$ trypsin-EDTA and incubated for 5 min. The pulmonary artery was then gently flushed with endothelial growth medium (EGM-2, Lonza) and supplemental foetal bovine serum (FBS, 10\%) to remove the endothelial cells. The harvested endothelial cells were cultured in EBM-2 in $100 \mathrm{~mm}$ plates in a humidified, normoxic incubator $\left(21 \% \mathrm{O}_{2}, 5 \% \mathrm{CO}_{2}\right)$ at $37^{\circ} \mathrm{C}$. PAECs were identified by their cobblestone morphology and positive staining for endothelial nitric oxide synthase (eNOS). Cells were subcultured at near confluence and used at passages 4-10.

\subsection{Pulmonary artery smooth muscle cell isolation}

Pulmonary arteries $<1 \mathrm{~mm}$ were dissected from the lungs of 5-day-old piglets $(n=5)$ and the surrounding adventitia and connective tissue removed. Pulmonary artery smooth muscle cell (PASMCs) were obtained from the cleaned arteries by enzymatic digestion with collagenase (5\%) using modified methods. ${ }^{19,20}$ The PASMCs were cultured in Dulbecco's modified Eagle Medium (DMEM) and supplemental FBS (10\%) in $100 \mathrm{~mm}$ plates in a humidified, normoxic incubator $\left(21 \% \mathrm{O}_{2}, 5 \% \mathrm{CO}_{2}\right)$ at $37^{\circ} \mathrm{C}$. PASMCs were identified by their typical elongated morphology ${ }^{19}$ and positive staining for smooth muscle cell myosin heavy chain and $\alpha$-actin. Cells were subcultured at near confluence and used at passages 3-5.

\subsection{PAEC and PASMC protocols}

To assess the effect of hypoxia on SNAT1, 2, 3, or 5 protein expression and citrulline uptake, confluent monolayers of PAECs or PASMCs from piglet primary cell lines were passaged from $100 \mathrm{~mm}$ plates to 6-well plates and cultured overnight in EGM-2 or DMEM under normoxic conditions. The next morning, the media was changed and the PAECs or PASMCs were placed into either a normoxic $\left(21 \% \mathrm{O}_{2}, 5 \% \mathrm{CO}_{2}, 37^{\circ} \mathrm{C}\right)$ or hypoxic $\left(4 \% \mathrm{O}_{2}, 5 \% \mathrm{CO}_{2}, 37^{\circ} \mathrm{C}\right)$ humidified environment. The hypoxic environment was carefully maintained at the desired levels of oxygen and $\mathrm{CO}_{2}$ using PROOX model 110 oxygen and $\mathrm{CO}_{2}$ control systems (Biospherix, Ltd., Redfield, NY, USA).

\subsection{Citrulline uptake}

After 24,48 , or $72 \mathrm{~h}$ in normoxic or hypoxic culture conditions, PAECs or PASMCs were washed three times with $2 \mathrm{~mL}$ of fresh sodium-HEPES buffer composed of the following: $122 \mathrm{mM} \mathrm{NaCl}, 3.3 \mathrm{mM} \mathrm{KCl}, 0.4 \mathrm{mM}$ $\mathrm{MgSO}_{4}, 1.2 \mathrm{mM} \mathrm{CaCl}, 1.2 \mathrm{mM} \mathrm{KH} 2 \mathrm{PO}_{4}, 10 \mathrm{mM}$ glucose and $25 \mathrm{mM}$ HEPES adjusted to $\mathrm{pH}$ of 7.4 with $10 \mathrm{mM} \mathrm{NaOH}$. Cells were incubated under normoxic conditions $\left(21 \% \mathrm{O}_{2}, 5 \% \mathrm{CO}_{2}, 37^{\circ} \mathrm{C}\right)$ with $0.25 \mu \mathrm{Ci} / \mathrm{mL}$ ${ }^{14} \mathrm{C}$-L-citrulline (specific activity: $56.3 \mathrm{mCi} / \mathrm{mmol}$; Perkin Elmer, Norwalk, CT, USA $)$ in the presence of a saturating concentration $(200 \mu M$ total concentration) of unlabelled citrulline using our previously described 
methods. ${ }^{21}$ Some PAECs or PASMCs were also incubated in the presence of system-selective competing amino acids. Competitors used to select for system A were glutamine, histidine, threonine, and leucine, each $10 \mathrm{mM}$ and chosen for use because these amino acids are preferentially transported by Systems N, ASC, or L, respectively. Competitors to select for system $\mathrm{N}$ were 2-methylaminoisobutyric acid, leucine, and threonine, each $10 \mathrm{mM}$ and chosen for use because these amino acids are transported by Systems A, L, or ASC, respectively. Incubations were stopped after 1, 5, and 10 min with ice-cold sodium-HEPES buffer using cells in different wells at each of the three time points. All cells were lysed with $1 \mathrm{M} \mathrm{NaOH}$ for $30 \mathrm{~min}$ at $37^{\circ} \mathrm{C}$. An aliquot of the lysate was transferred to a scintillation vial, LSC cocktail (Fisher Scientific, Pittsburgh, PA, USA) was added and radioactivity was measured in a scintillation counter (Beckman LS 6500; Brea, CA, USA). The remainder of the lysate was used for protein determination by the bicinchoninic acid protein assay (Pierce, Rockford, IL, USA). Uptake of L-citrulline was expressed as CPM per mg protein.

\subsection{Protein analysis by immunoblot technique}

After 24,48 , or $72 \mathrm{~h}$ in normoxic or hypoxic environments, PAECs or PASMCs were washed two times with PBS, then collected and stored at $-80^{\circ} \mathrm{C}$. Frozen PAECs, PASMCs, pulmonary arteries, or lung samples were crushed under liquid $\mathrm{N}_{2}$ in a pre-chilled mortar and pestle into a fine powder, transferred to a tube containing homogenization buffer with protease inhibitors, and then sonicated. Protein concentrations for all homogenates were determined by the protein assay (Bradford). Using our previously described methods, ${ }^{22}$ supernatants were applied to tris-glycine pre-cast 4-20\% polyacrylamide gels (Invitrogen, Carlsbad, CA, USA) so that equal amounts of protein were loaded. Electrophoresis was carried out and the proteins were transferred from the gel to a nitrocellulose membrane. The membrane was incubated at room temperature in PBS containing 7.5\% non-fat dried milk and $0.1 \%$ Tween-20 to block non-specific protein binding. To detect the protein of interest, the nitrocellulose membrane was incubated overnight with the primary antibody from ABCAM (Cambridge, MA, USA) (SNAT1, 1:800 for PAECs or 1:1000 for PASMCs, the lung, and pulmonary artery homogenates; SNAT2, 1:500 for PAECs or 1: 1000 for the lung and pulmonary artery homogenates; SNAT3, 1:1000 for PAECs or 1:500 for the lung and pulmonary artery homogenates; SNAT5, 1:900 for PAECs or 1:1000 for the lung and pulmonary artery homogenates) diluted in PBS containing $0.1 \%$ Tween-20 and $1 \%$ non-fat dried milk (carrier buffer); followed by incubation with a horseradish peroxidaseconjugated secondary antibody (Zymed) diluted in the carrier buffer (1:5000). The membranes were developed using enhanced chemiluminescence reagents (ECL, Amersham CO.) and the chemiluminescent signal was captured on X-ray film (ECL Hyperfilm, Kodak). Similar procedures were followed to reprobe the membranes for either $\beta$-actin (Sigma, 1:50,000 on membranes used for PAECs) or GAPDH (ABCAM, 1:1000 on membranes used for the lung, pulmonary artery, and PASMC homogenates). The bands for each protein were quantified using densitometry.

\subsection{Immunolocalization of SNAT1 in lungs}

Paraffin-embedded lung sections from 5-day-old control piglets were subjected to antigen retrieval using high $\mathrm{pH}$ Target Retrieval Solution (Dako, Carpinteria, CA, USA). Sections were labelled using primary antibodies against SNAT1 (1:100, ABCAM) or eNOS (1:100, BD, San Jose, CA, USA). Alexa-fluorophore containing secondary antibodies (Invitrogen) and TO-PRO-3 (Invitrogen) nuclear stain were used for visualization. Images were acquired using a TCS SP2 laser scanning confocal system (Leica Microsystems, Buffalo Grove, IL, USA).

\subsection{Lung amino acid determination}

Frozen lung samples were used to measure levels of the following amino acids: citrulline, glutamine (known to be transported by System $\mathrm{N}$ and
System A), alanine (known to be transported by System A but not by System $N$ ), and histidine (known to be preferentially transported by System N). For amino acid analyses, a $20 \mathrm{mg}$ piece of frozen lung tissue was homogenized in $100 \mu \mathrm{L} 1$ ysis buffer, allowed to sit on ice for $30 \mathrm{~min}$, and then centrifuged at $400 \times \mathrm{g}$ to remove the largest pieces of lung tissue. Next, $100 \mu \mathrm{L}$ of the supernatant was diluted with $200 \mathrm{~mL}$ of $0.15 \mathrm{M}$ sulfosalicylic acid, allowed to sit on ice for $30 \mathrm{~min}$, and then centrifuged to precipitate the larger protein molecules. Amino acid levels were measured in the supernatant using a Hitachi L8800 amino acid analyzer (Hitachi USA, San Jose, CA, USA). ${ }^{2}$

\subsection{Data analyses}

Data are presented as mean \pm SEM. An unpaired $t$-test was used to compare data between normoxic and hypoxic tissues. $P$-values $<0.05$ were considered statistically significant.

\section{Results}

SNAT1 protein expression was greater in PAECs cultured under hypoxic conditions compared with PAECs cultured under normoxic conditions for all time periods studied: 24, 48, and $72 \mathrm{~h}$ (Figure 2A). SNAT2 (Figure 2B) and SNAT5 (Figure 2D) protein expression did not differ between PAECs cultured under normoxic vs. hypoxic conditions at any time point. SNAT3 protein (Figure 2C) was reduced in PAECs cultured in hypoxia for $48 \mathrm{~h}$ but not for 24 or $72 \mathrm{~h}$ compared with PAECs cultured in normoxia.

We also determined whether in vitro findings in PAECs cultured under prolonged hypoxic conditions correlate with in vivo changes in SNAT expression in the lungs and pulmonary arteries of piglets with pulmonary hypertension induced by prolonged exposure to hypoxia. Consistent with the in vitro data (Figure 2A), SNAT1 protein expression was increased in lungs from both age groups of hypoxic piglets (Figure $3 \mathrm{~A}$ ). Although not discernibly altered in pulmonary arteries from piglets exposed to in vivo hypoxia for 3 days (Figure 4A), SNAT1 protein expression was increased in pulmonary arteries from piglets exposed to in vivo hypoxia for 10 days (Figure 4A). We found no difference in SNAT2, SNAT3, or SNAT5 protein expression in lungs (Figure 3) or pulmonary arteries (Figure 4) of hypoxic piglets vs. lungs or pulmonary arteries of their comparable age normoxic control piglets.

Next, we performed a series of studies to determine whether exposure to prolonged hypoxia alters L-citrulline uptake in PAECs from newborn piglets. ${ }^{14} \mathrm{C}$-L-citrulline uptake was increased in PAECs cultured under hypoxic conditions for all three time periods, 24, 48, and $72 \mathrm{~h}$ (Figure 5A). By selectively inhibiting System A (SNAT1/2) or System N (SNAT3/5), we found that for all three time points the enhanced ${ }^{14} \mathrm{C}$-L-citrulline uptake was largely due to System $\mathrm{A}$ transport (Figure 5B).

We also determined whether exposure to hypoxia for $72 \mathrm{~h}$ alters SNAT1 expression or L-citrulline uptake in PASMCs from newborn piglets. Unlike PAECs (Figure 2 and Figure 5), neither SNAT1 expression (Figure 6A) nor ${ }^{14} \mathrm{C}$-L-citrulline uptake (Figure 6B) were altered in PASMCs exposed to prolonged in vitro hypoxia.

Immunohistochemistry was performed to determine whether cell types in addition to PAECs and PASMC express SNAT1 in lungs of piglets. As shown in Supplementary material online, Figure S1, SNAT1 is widely expressed in multiple cell types, including in airway epithelial cells.

Amino acid analysis revealed that citrulline levels were greater in the lungs of both groups of hypoxic piglets than in lungs of their comparable age control piglets (Table 1). Alanine levels were increased in 
A SNAT1 $24 \mathrm{~h}$

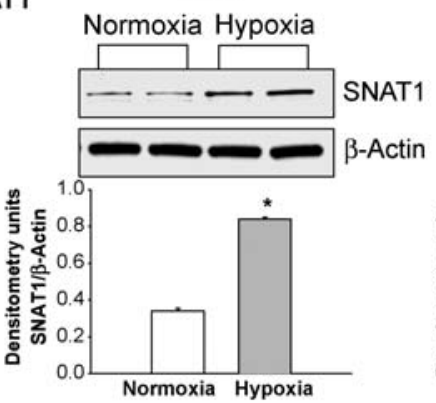

$24 \mathrm{~h}$

B SNAT2
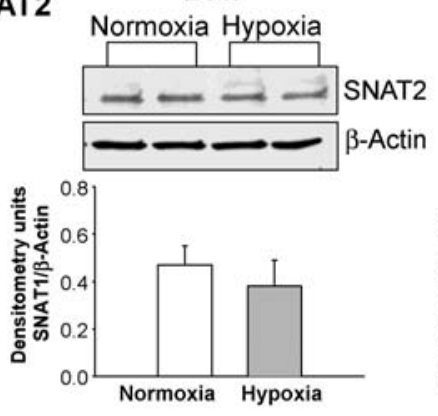

C SNAT3

$24 \mathrm{~h}$

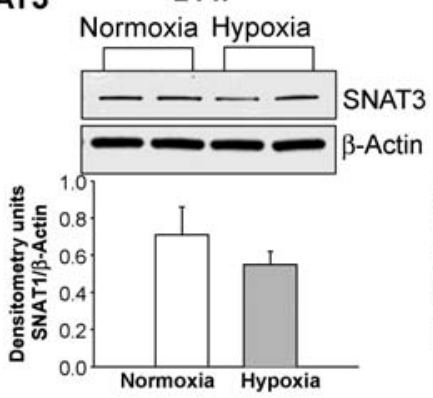

D SNAT5

$24 \mathrm{~h}$

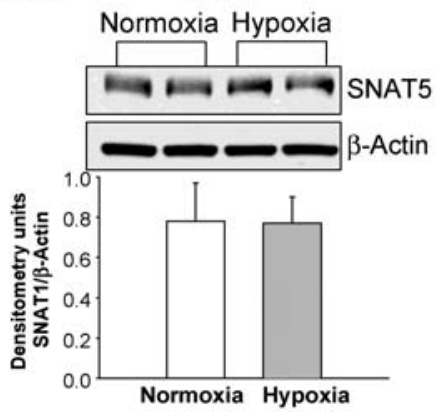

$48 \mathrm{~h}$

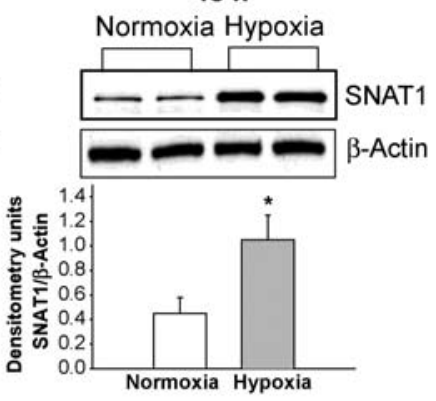

$48 \mathrm{~h}$

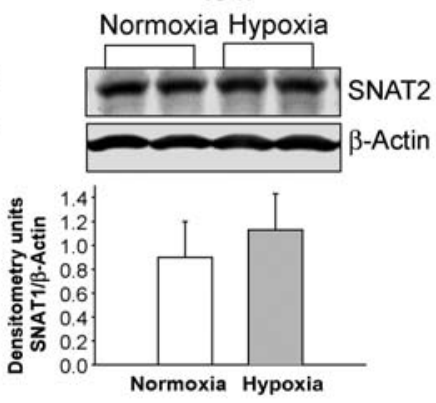

$48 \mathrm{~h}$

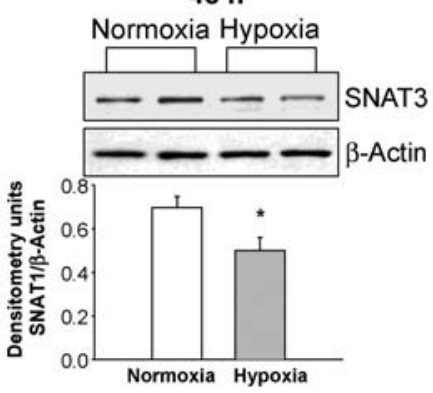

$48 \mathrm{~h}$

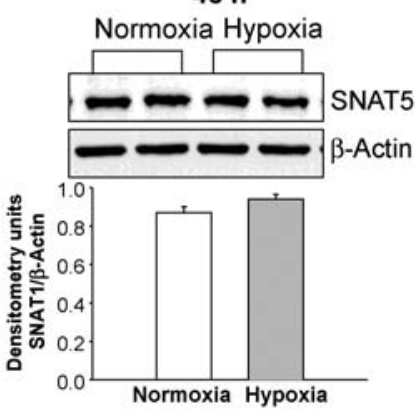

$72 \mathrm{~h}$

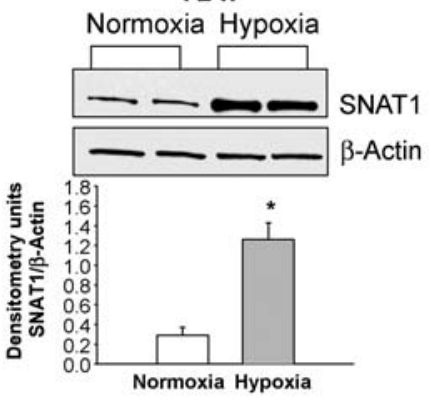

$72 \mathrm{~h}$

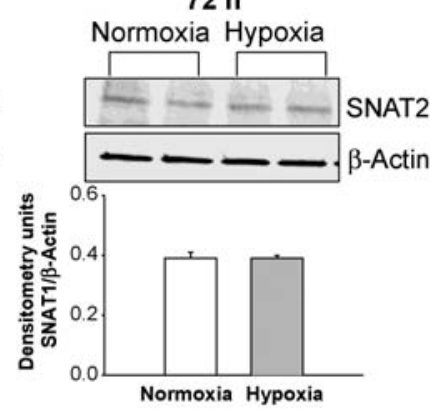

$72 \mathrm{~h}$

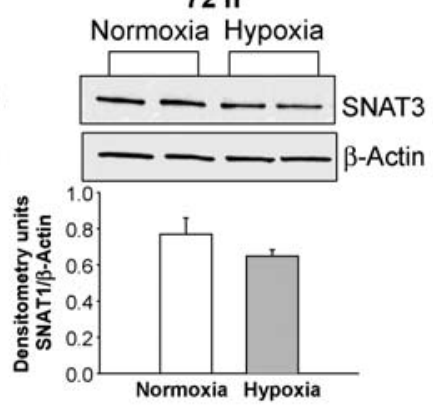

$72 \mathrm{~h}$

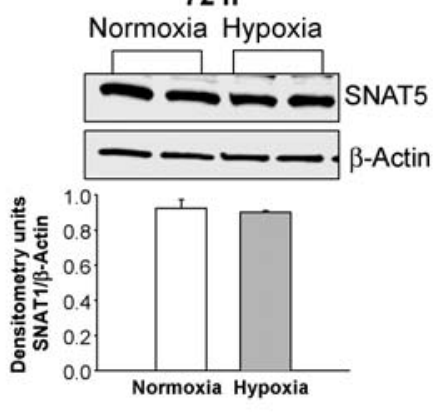

Figure 2 Immunoblot results and corresponding densitometry for SNAT1, 2, 3, and 5 protein expression normalized to $\beta$-actin in PAECs cultured under normoxic and hypoxic conditions for 24,48 , or $72 \mathrm{~h}$. (A-D) Representative immunoblots and corresponding densitometry of studies that were performed in duplicate or triplicate using PAECs from four to five different piglets. *Different from normoxia; $P<0.05$.

lungs of piglets exposed to 10 days of hypoxia, whereas histidine levels were decreased in lungs of both groups of hypoxic piglets.

\section{Discussion}

In this investigation, we report a number of novel findings regarding prolonged hypoxia, SNATs protein expression, and L-citrulline transport in lungs of newborn piglets. In particular, we show for the first time that prolonged hypoxia augments both SNAT1 protein expression and L-citrulline uptake in PAECs from newborn piglets.

SNATs are classically categorized as System A or System N, dependent in part on their functional properties and patterns of regulation. System A subtypes, which include SNAT1, SNAT2, and SNAT4 are characterized by a broader amino acid substrate profile than System N subtypes, which include SNAT3 and SNAT5. ${ }^{12,23}$ More specifically, SNAT1 and SNAT2 (also referred to as ATA1 and ATA2 


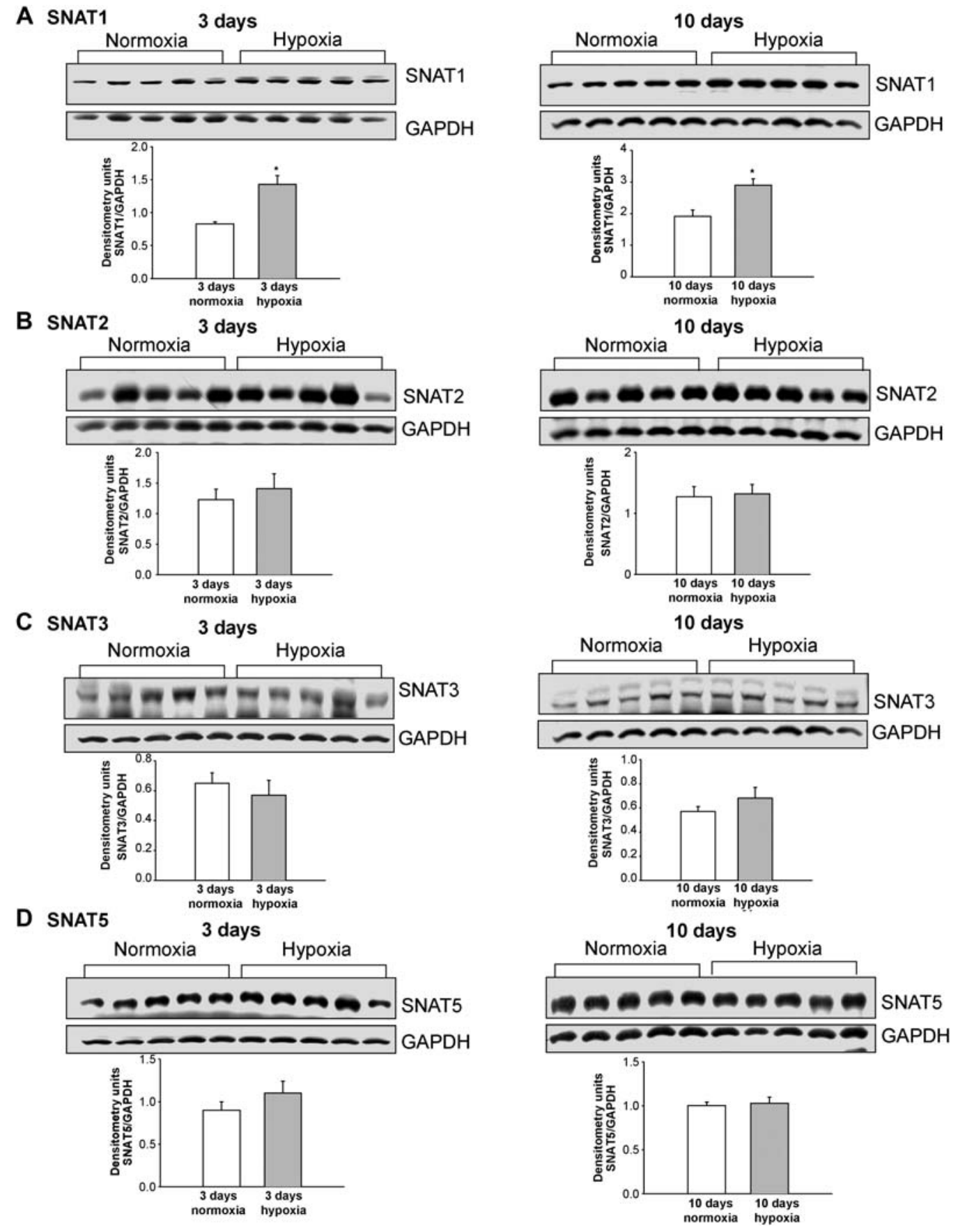

Figure $3(A-D)$ Immunoblot results and corresponding densitometry for SNAT protein expression normalized to GAPDH in lungs from piglets raised under normoxic and hypoxic conditions for either 3 days ( $n=5$ normoxic and $n=5$ hypoxic piglets) or 10 days ( $n=5$ normoxic piglets and $n=5$ hypoxic piglets); *different from normoxic; $P<0.05$.

respectively) show a high affinity to alanine, serine, proline, and glycine but also recognize $\mathrm{N}$-methylated amino acids, like 2methylaminisobutyric acid. ${ }^{12,24}$ SNAT3 (also referred to as SN1 or NAT) recognizes the classic System $N$ substrates, ${ }^{23}$ glutamine, asparagine, and histidine, whereas SNAT5 (also known as SN2) favours serine. ${ }^{25}$ SNATs are found in most mammalian cells. ${ }^{11,12}$ Our finding that SNAT1 is expressed in multiple lung cell types, including airway epithelial cells, was therefore not surprising. Moreover, it is well known that a number of different transport systems may occur in the same cell membrane. In this regard and consistent with our findings, SNAT1, SNAT2, SNAT3, and SNAT5 have previously been reported to be expressed in lung tissue. ${ }^{12,25,26}$ SNATs expression may differ between tissues. For example, SNAT4 is considered to be liver specific ${ }^{12}$ and was not evaluated by us.

The transport of neutral amino acids into endothelial cells has been studied for decades. ${ }^{9}$ However, likely due to the unknown molecular identity of these transporters until very recently, ${ }^{12}$ information about the expression of SNAT1, 2, 3, 4, and 5 in endothelial cells from any 

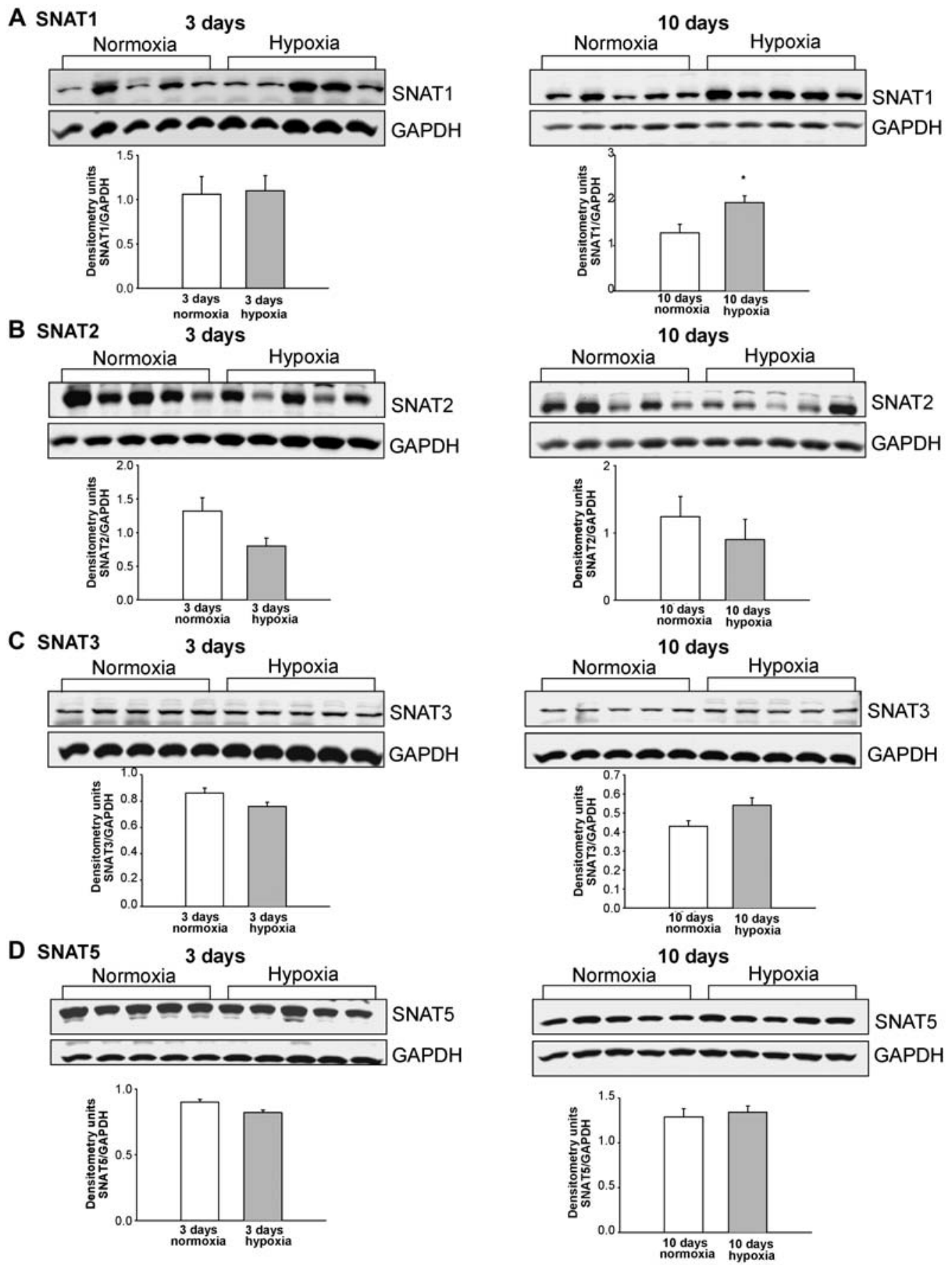

Figure $4(A-D)$ Immunoblot results and corresponding densitometry for SNAT protein expression normalized to GAPDH in pulmonary arteries from piglets raised under normoxic and hypoxic conditions for either 3 days $(n=5$ normoxic piglets and $n=5$ hypoxic piglets) or 10 days $(n=5$ normoxic piglets and $n=5$ hypoxic piglets); *different from normoxic; $P<0.05$.

vascular bed is scarce. Specifically, cells from the human umbilical venous endothelial cell (HUVEC)-derived permanent line EA.hy926 and primary HUVECs were shown by quantitative real-time RT-PCR to express SNAT3. ${ }^{27}$ To our knowledge, there are no reports regarding the expression of the SNAT family in pulmonary vascular endothelial cells. We add to the literature and show that SNAT1, 2, 3, and 5 are expressed in PAECs from newborn piglets.

There is also very limited information available about the impact of hypoxia on SNAT expression and/or activity in any tissue or cell type.
In cultured cells from the human placenta, $24 \mathrm{~h}$ of hypoxia reduced the expression and function of System A transporters. ${ }^{28}$ Six hours of hypoxia reduced the substrate affinity of System A transporters in cultured human lung fibroblasts. ${ }^{29}$ SNAT1 expression decreased in rat pup brains $24 \mathrm{~h}$ after hypoxia-ischaemia but increased 7 days later. $^{30}$ We now report that 24,48 , and $72 \mathrm{~h}$ of in vitro hypoxia increases SNAT1 expression in PAECs, that 10 days in vivo hypoxia increases SNAT1 expression in pulmonary arteries, and that 3 and 10 days in vivo exposure to hypoxia increases lung SNAT1 expression. 
A Total Uptake

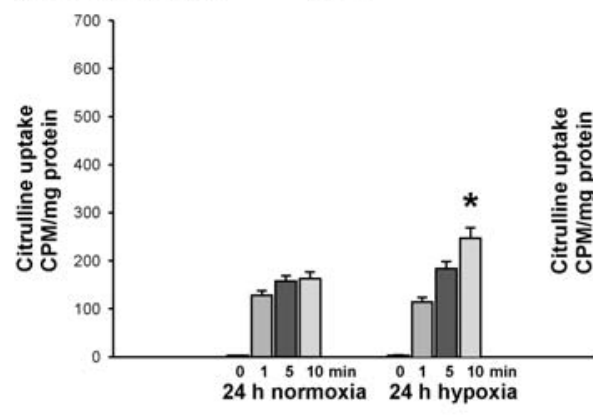

$24 \mathrm{~h}$
B System A-mediated uptake

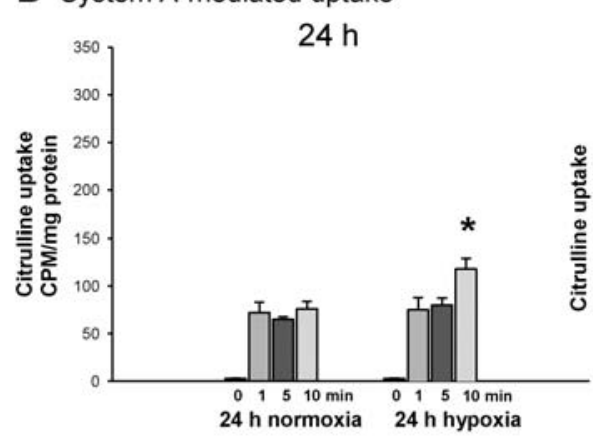

$48 \mathrm{~h}$

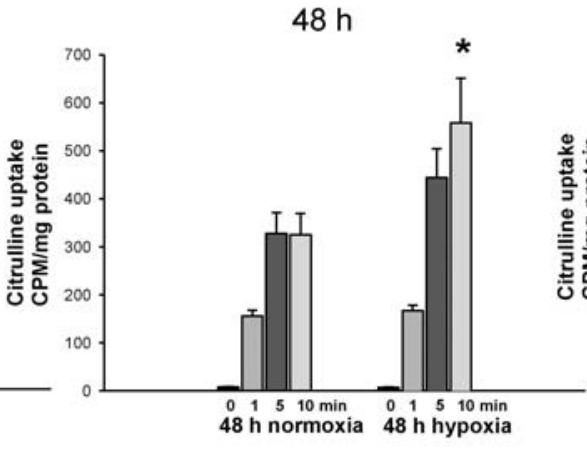

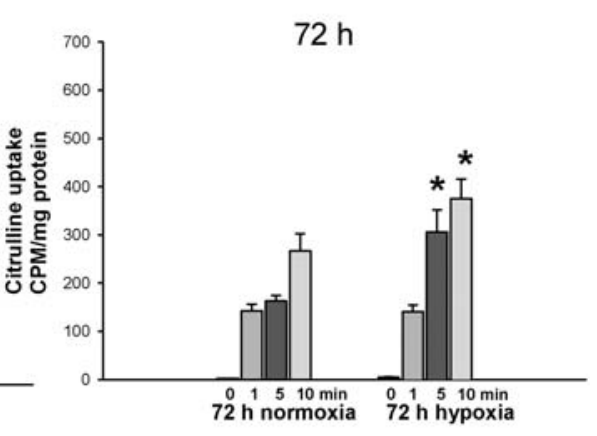

$72 \mathrm{~h}$
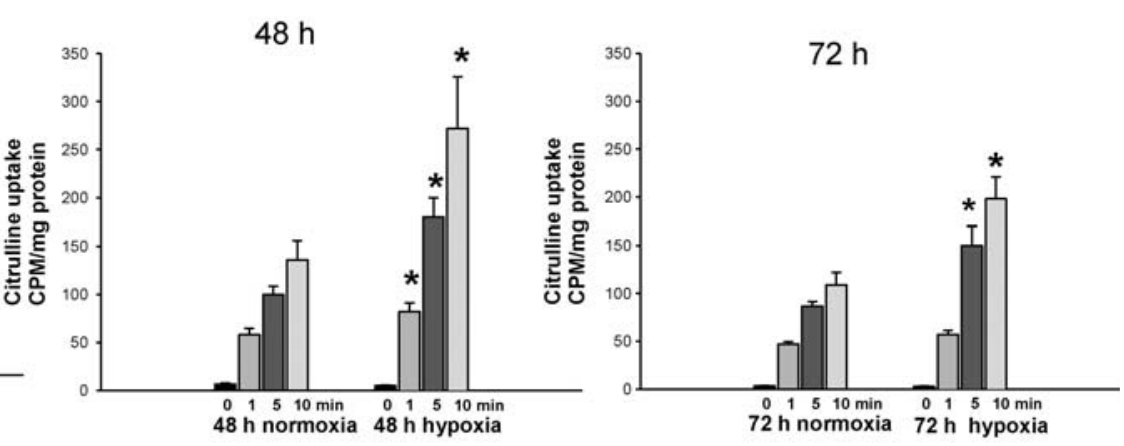

C. System $\mathrm{N}$-mediated uptake
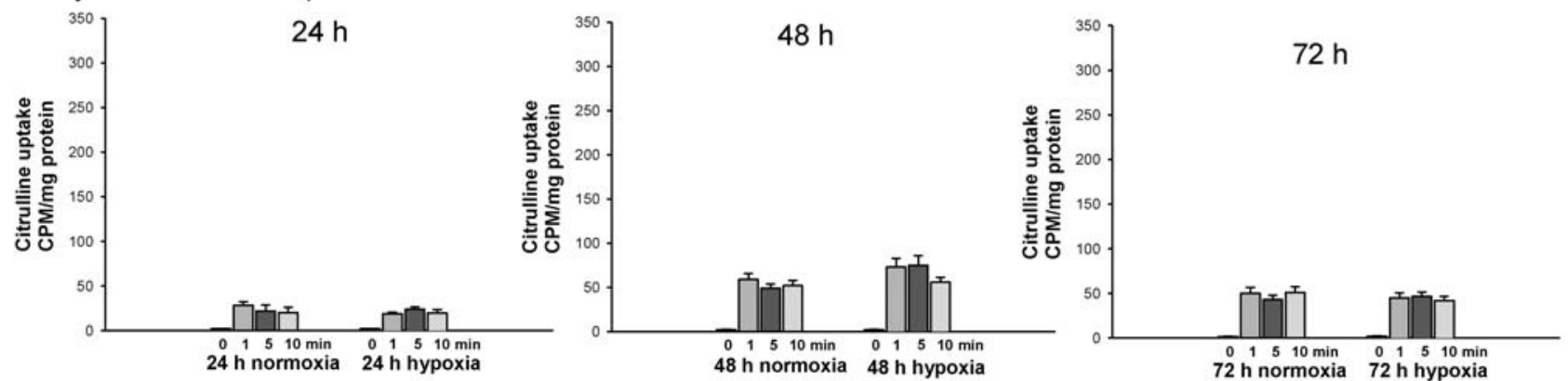

Figure 5 Citrulline uptake in PAECs cultured under normoxic and hypoxic conditions for 24, 48, or 72 h: (A) total uptake; (B) System A-mediated uptake (determined by the use of amino acid competitors to select for System A: glutamine, histidine, threonine, and leucine, amino acids preferentially transported by Systems N, ASC, and L, respectively); (C) System N-mediated uptake (determined by the use of amino acid competitors to select for System N: 2-methylaminoisobutyric acid, leucine, and threonine, amino acids preferentially transported by Systems A, L, or ASC, respectively). All studies were performed in triplicate using PAECs from three to four different piglets. *Different from normoxic; $P<0.05$.

In addition to altering transporter expression, we found that prolonged in vitro hypoxia for durations of 24,48 , and $72 \mathrm{~h}$ increases the functional ability of PAECs to transport citrulline. Previous investigators found no change in citrulline transport in PAECs from adult pigs cultured for up to $24 \mathrm{~h}$ in hypoxia. ${ }^{16}$ The discrepancy in findings could be due to the age of the animals, the degree of hypoxia, or to different experimental conditions. Of great interest, our findings with competitive transport inhibitors show that the hypoxia-induced increase in citrulline transport is due to System A, which includes SNAT1. Our findings are in line with the many studies that have shown that changes in function and expression of System A transporters occur in the placenta and mammary gland during pregnancy. ${ }^{13,31-33}$ Moreover, changes in SNAT1 have recently been described in cardiomyocytes and astrocytes during oxidative stress. ${ }^{14,15}$ It is also important to note that our findings point to a role for System $A$ in citrulline transport in normoxic PAECs.

There is some, albeit limited, information available about citrulline transport in organs other than lungs and in cells other than endothelial cells. For example, studies with rat kidney slices found that basolateral L-citrulline uptake was largely due to the $\mathrm{Na}^{+}$-independent organic anion transporter, OAT1. ${ }^{34}$ Yet, in studies with rat renal proximal tubular epithelial cells and the human kidney proximal tubular epithelial cell line, HK-2, apical uptake of L-citrulline was shown to be mediated by at least two distinct $\mathrm{Na}^{+}$-dependent transport systems and one $\mathrm{Na}^{+}$-independent transport system. ${ }^{35}$ Likewise, studies with Caco-2 cells, a model of human intestinal epithelial cells, found that apical L-citrulline uptake was mediated both by $\mathrm{Na}^{+}$dependent (via System $\mathrm{B}^{(0,+)}$ ) and $\mathrm{Na}^{+}$-independent (via Systems 


\section{A SNAT1 expression}

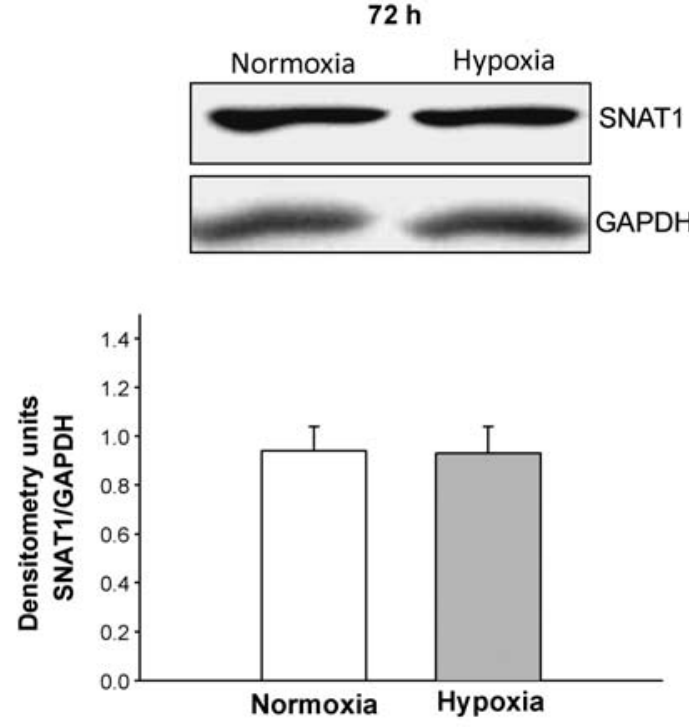

\section{B Citrulline uptake}


Figure 6 SNAT1 protein expression and citrulline uptake in PASMC cultured under normoxic and hypoxic conditions for $72 \mathrm{~h}$. (A) Representative immunoblot for SNAT1 and corresponding densitometry for SNAT1 normalized to GAPDH in studies performed using PASMC from five different piglets. (B) Total, System A, and System N-mediated citrulline uptake in studies performed in triplicate with PASMC from two different piglets.

Table I Amino acid levels in piglet lungs

\begin{tabular}{|c|c|c|c|c|}
\hline & Citrulline, $\mu \mathrm{M}$ & Alanine, $\mu M$ & Glutamine, $\mu \mathrm{M}$ & Histidine, $\mu M$ \\
\hline Normoxia $(n=4)$ & $3 \pm 1$ & $331 \pm 41$ & $1389 \pm 50$ & $21 \pm 3$ \\
\hline \multicolumn{5}{|c|}{ Ten-day exposure group } \\
\hline Normoxia $(n=7)$ & $4 \pm 1$ & $272 \pm 19$ & $1380 \pm 57$ & $20 \pm 1$ \\
\hline Hypoxia $(n=7)$ & $16^{a} \pm 3$ & $419^{a} \pm 50$ & $1334 \pm 89$ & $10^{a} \pm 1$ \\
\hline
\end{tabular}


$\mathrm{L}$ and $\mathrm{b}^{(0,+)}$ ) systems. ${ }^{36}$ In contrast, a study with everted rat small intestinal sacs indicated that L-citrulline uptake is predominantly $\mathrm{Na}^{+}$ dependent. ${ }^{37} \mathrm{Na}^{+}$-independent System $\mathrm{L}$ was shown to mediate L-citrulline uptake in a variety of neural cell cultures; ${ }^{38}$ whereas L-citrulline transport in rat aortic smooth muscle cells was shown to be primarily mediated by System $L$ but was also partially dependent on System N ${ }^{39}$ L-Citrulline transport in macrophages also appears to be partially $\mathrm{Na}^{+}$dependent. ${ }^{40}$ Thus, the transporters involved in L-citrulline uptake may not be the same in all organs and cells.

More relevant to our novel findings, we know of only a few other studies that have evaluated citrulline transport in endothelial cells of any vascular bed. Citrulline uptake by bovine aortic endothelial cells was shown to be modulated by $\mathrm{P}^{1}, \mathrm{P}^{4}$-diadenosine $5^{\prime}$-tetraphosphate $\left(A p_{4} A\right)^{2}$, an $\alpha, \omega$-dinucleotide found in platelets. ${ }^{41}$ Glutamine, an amino acid that is transported by both System $A$ and $N$, has been shown to compete with and thereby inhibit citrulline transport in endothelial cells of the systemic circulation, including HUVECs, ${ }^{27}$ bovine aortic endothelial cells, bovine coronary endothelial cells, and human mesenteric microvascular endothelial cells. ${ }^{42}$ Notably, whether System $\mathrm{A}$ or $\mathrm{N}$ transporters were involved with citrulline transport was not evaluated in any of these studies.

Of interest, a few studies have evaluated transport of neutral amino acids other than L-citrulline in PAECs. In particular, the L-glutamine influx in porcine PAECs ${ }^{43}$ and rat lung microvascular endothelial cells ${ }^{44}$ was shown to be predominantly mediated by the $\mathrm{Na}^{+}$dependent system, ASC. L-Histidine uptake in rat lung microvascular endothelial cells was shown to involve both the $\mathrm{Na}^{+}$-dependent System $\mathrm{N}$ and the $\mathrm{Na}^{+}$-independent System L. ${ }^{8}$ L-Glutamic acid uptake in bovine PAECs was previously shown to be mostly $\mathrm{Na}^{+}$dependent. ${ }^{45}$ Taken together, these studies show that $\mathrm{Na}^{+}$-dependent systems are involved in neutral amino acid transport in PAECs. However, the role of these systems in citrulline transport in PAECs has not been previously evaluated.

Our results indicate that Systems $A$ and $N$ account for $\sim 60 \%$ of total citrulline uptake in PAECs (Figure 5). Delineation of the other transport systems, including $\mathrm{Na}^{+}$-independent systems, involved in citrulline uptake in PAECs will require future studies. Regardless, our findings are provocative as they identify the system of transporters, System A, responsible for an increase in citrulline transport under hypoxic conditions in PAECs.

It is important to note that our findings with PASMCs contrast with our findings with PAECs. Indeed, the lack of change in SNAT1 and citrulline transport in hypoxic PASMCs indicates that exposure to prolonged hypoxia does not influence citrulline transport similarly in all lung cell types. Moreover, findings with PASMCs indicate that hypoxia-induced alterations in lung levels of citrulline are unlikely to be due to any contribution from PASMCs.

Our findings of increased citrulline levels in lungs of hypoxic piglets merit some comment. First, the concomitant elevation in alanine and reduction in histidine support the idea that System $A$ transporters are responsible for the enhanced amino acid levels. This is because alanine is transported by System $A$ and not by System $N$ and histidine is preferentially transported by System N. ${ }^{12}$ Secondly, we know of no other studies that have evaluated lung citrulline levels in an animal model of chronic hypoxia-induced pulmonary hypertension. However, lungs of lambs with pulmonary hypertension induced by an elevated blood flow were found to have diminished citrulline levels. ${ }^{46}$ The physiological impact of altered lung citrulline levels in the context of pulmonary hypertension is not yet clear.
In summary, the novel findings in this study provide important insights into a little explored area of NO biology in the pulmonary circulation. In particular, we show that prolonged hypoxia increases SNAT1 expression with accompanying increases in System Amediated citrulline transport in PAECs of newborn piglets. These in vitro findings appear to have in vivo relevance as both citrulline levels and SNAT1 protein are increased in lungs of piglets with chronic hypoxia-induced pulmonary hypertension. In light of recent publications demonstrating the ameliorative effects of supplemental citrulline in two different models of neonatal pulmonary hypertension, ${ }^{2,4}$ an increase in SNAT1 expression and concomitant enhanced ability to transport citrulline could be an important regulatory mechanism capable of modulating NO production, particularly under conditions of chronic hypoxia. Manipulation of SNAT1 expression or citrulline transport (Figure 1) merits further investigation as a novel therapeutic approach for neonatal patients with pulmonary hypertension.

\section{Supplementary material}

Supplementary material is available at Cardiovascular Research online.

Conflict of interest: C.F., J.A., and M.S. are listed as inventors on a patent application to treat lung diseases with intravenous citrulline.

\section{Funding}

This work was supported by the National Institutes of Health (HL97566 to C.F., HL68572 to C.F., HL075511 to J.A., ES07331 to M.A., ES10563 to M.A. and HD061221 to M.S.).

\section{References}

1. Solomonson LP, Flam BR, Pendleton LC, Goodwin BL, Eichler DC. The caveolar nitric oxide synthase/arginine regneration system for $\mathrm{NO}$ production in endothelial cells. J Exp Biol 2003;206:2083-2087.

2. Ananthakrishnan M, Barr FR, Summar ML, Smith HA, Kaplowitz M, Cunningham G et al. L-Citrulline ameliorates chronic hypoxia-induced pulmonary hypertension in newborn piglets. Am J Physiol Lung Cell Mol Physiol 2009;297:L506-L511.

3. Erez A, Chen Y, Oleg A, Shchelochov AM, Bertin TK, Jiang M-M et al. Requirement of argininosuccinate lyase for systemic nitric oxide production. Nat Med 2011;17: 1619-1626.

4. Vadivel A, Aschner JL, Rey-Parra GJ, Magarik J, Zeng H, Summar M et al. L-Citrulline attenuates arrested alveolar growth and pulmonary hypertension in oxygen-induced lung injury in newborn rats. Pediatr Res 2010;68:519-525.

5. Neill MA, Aschner J, Barr F, Summar ML. Quantitative RT-PCR comparison of the urea and nitric oxide cycle gene transcripts in adult human tissues. Mol Genet Metab 2009;97:121-127.

6. Cynober L, Moinard C, Bandt J-PD. Citrulline: a new major signaling molecule or just another player in the pharmaconutrition game? Clin Nutr 2010;29:545-551.

7. Windmueller HG, Spaeth AE. Source and fate of circulating citrulline. Am J Physiol Endocrinol Metab 1981;241:E473-E480.

8. Sakurai E, Sakurada T, Ochiai Y, Yamakami J, Tanaka Y. Stereoselective transport of histidine in rat lung microvascular endothelial cells. Am J Physiol Lung Cell Mol Physiol 2002;282:1192-1197.

9. Mann GE, Yudilevich DL, Sobrevia L. Regulation of amino acid and glucose transporters in endothelial and smooth muscle cells. Physiol Rev 2003;83:183-252.

10. McGivan JD, Pastor-Anglada M. Regulatory and molecular aspects of mammalian amino acid transport. Biochem J 1994;299:321-334.

11. Palacin M, Estevez R, Bertran J, Zorzano A. Molecular biology of mammalian plasma membrane amino acid transporters. Physiol Rev 1998;78:969-1054.

12. Mackenzie B, Erickson JD. Sodium-coupled neutral amino acid (System N/A) transporters of the SLC38 gene family. Pflugers Arch 2004;447:784-795.

13. Desforges M, Greenwood SL, Glazier JD, Westwood M, Sibley CP. The contribution of SNAT1 to system A amino acid transporter activity in human placental trophoblast. Biochem Biophys Res Commun 2010;398:130-134.

14. King N, Lin H, Suleiman M-S. Oxidative stress increases SNAT1 expression and stimulates cysteine uptake in freshly isolated rat cardiomyocytes. Amino Acids 2011;40: 517-526.

15. Milatovic D, Yin Z, Gupta RC, Sidoryk M, Albrecht J, Aschner JL et al. Manganese induces oxidative impairment in cultured rat astrocytes. Toxicol Sci 2007;98:198-205. 
16. Su Y, Block ER. Hypoxia inhibits L-arginine synthesis from L-citrulline in porcine pulmonary artery endothelial cells. Am J Physiol Lung Cell Mol Physiol 1995;269: L581-L587.

17. Fike CD, Kaplowitz MR, Thomas CJ, Nelin LD. Chronic hypoxia decreases nitric oxide production and endothelial nitric oxide synthase in newborn pig lungs. Am J Physiol Lung Cell Mol Physiol 1998;274:L517-L526.

18. Block ER, Patel JM, Angelides KJ, Sheridan NP, Garg LC. Hyperoxia reduces plasma membrane fluidity: a mechanism for endothelial cell dysfunction. J Appl Physiol 1986; 60:826-835.

19. Gunther S, Alexander RW, Atkinson WJ, Gimbrone MA. Functional angiotensin II receptors in cultured vascular smooth muscle cells. J Cell Biol 1982;92:289-298.

20. Rothman A, Kulik TJ, Taubman MB, Berk BC, Smith CWJ, Nadal-Ginard B. Development and characterization of a cloned rat pulmonary arterial smooth muscle cell line that maintains differentiated properties through multiple subcultures. Circulation 1992; 86:1977-1986

21. Sidoryk-Wegrzynowicz M, Lee E, Albrecht J, Aschner M. Manganese disrupts astrocyte glutamine transporter expression and function. J Neurochem 2009;110:822-830.

22. Fike CD, Aschner JL, Zhang Y, Kaplowitz MR. Impaired NO signaling in small pulmonary arteries of chronically hypoxic newborn pigs. Am J Physiol Lung Cell Mol Physiol 2004;286:1244-1254.

23. Kilberg MS, Handlogten ME, Christensen HN. Characteristics of amino acid transport system in rat liver for glutamin, asparagine, histidine, and closely related analogs. J Biol Chem 1980;255:4011-4019.

24. Ling R, Bridges CC, Sugawara M, Fujita T, Leibach FH, Prasad PD et al. Involvement of transporter recruitment as well as gene expression in the substrate-induced adaptive regulation of amino acid transport system A. Biochim Biophys Acta 2001;1512:15-21.

25. Nakanishi T, Sugawara M, Huang W, Martindale RG, Leibach FH, Ganapathy ME et al. Structure, function, and tissue expression pattern of human SN2, a subtype of the amino acid transport system N. Biochem Biophys Res Commun 2001;281:1343-1348.

26. Nakanishi T, Kekuda R, Fei YJ, Hatanaka T, Sugawara M, Martindale RG et al. Cloning and functional characterization of a new subtype of the amino acid transport system N. Am J Physiol Cell Physiol 2001;281:C1757-C1768.

27. Simon A, Plies L, Habermeier A, Martine U, Reining M, Closs El. Role of neutral amino acid transport and protein breakdown supply of nitric oxide synthase in human endothelial cells. Circ Res 2003;93:813-820.

28. Nelson DM, Smith SD, Furesz TC, Sadovsky Y, Ganapathy V, Parvin CA et al. Hypoxia reduces expression and function of system $A$ amino acid transporters in cultured term human trophoblasts. Am J Physiol Cell Physiol 2003;284:C310-C315.

29. Berk JL, Hatch CA, Goldstein RH. Hypoxia inhibits amino acid uptake in human lung fibroblasts. J Appl Physiol 2000;89:1425-1431.

30. Leibovici A, Rossignol C, Montrowl JA, Erickson JD, Varoqui H, Watanabe M et al. The effects of hypoxia-ischemia on neutral amino acid transporters in the developing rat brain. Dev Neurosci 2007;29:268-274.
31. Desforges M, Lacey HA, Glazier JD, Greenwood SL, Mynett KJ, Speake PF et al. SNAT4 isoform of system A amino acid transporter is expressed in human placenta. Am J Physiol Cell Physiol 2006;290:C305-C312.

32. Jones HN, Ashworth C], Page KR, McArdle HJ. Cortisol stimulates system A amino acid transport and SNAT2 expression in a human placental cell line (BeWo). Am J Physiol Endocrinol Metab 2006;291:E596-E603.

33. Lopez A, Torres N, Ortiz V, Aleman G, Hernandez-Pando R, Tovar AR. Characterization and regulationof the gene expression of amino acid transport system A (SNAT2) in rat mammary gland. Am I Physiol Endocrinol Metab 2006;291: E1059-E1066

34. Nakakariya M, Shima Y, Shirasaka Y, Mitsuoka K, Nakanishi T, Tamai I. Organic anion transporter OAT1 is involved in renal handling of citruliine. Am J Physiol Renal Physiol 2009:297:F71-F79.

35. Mitsuoka K, Shirasaka Y, Fukushi A, Sato M, Nakamura T, Nakanishi T et al. Transport characteristics of L-citrulline in reanl apical membrane of proximal tubular cells. Biopharm Drug Dispos 2009;30:126-137.

36. Bahri S, Curis E, Wafi FZE, Aussel C, Chaumeil JC, Cynober L et al. Mechanisms and kinetics of citrulline uptake in a model of human intestinal epithelial cells. Clin Nutr 2008;27:872-880.

37. Vadgama JV, Evered DF. Characteristics of L-citrulline transport across rat small intestine in vitro. Pediatr Res 1992;32:472-478.

38. Schmidlin A, Fischer S, Wiesinger $\mathrm{H}$. Transport of L-citrulline in neural cell cultures. Dev Neurosci 2000;22:393-398.

39. Wileman SM, Mann GE, Pearson JD, Baydoun AR. Role of L-citrulline transport in nitric oxide synthesis in rat aortic smooth muscle cells activated with LPS and interferon- $\gamma$. Br J Pharmacol 2003;140:179-185.

40. Baydoun AR, Bogle RG, Pearson JD, Mann GE. Discrimination between citrulline and arginine transport in activated murine macrophages: inefficient synthesis of $\mathrm{NO}$ from recycling of citrulline to arginine. Br J Pharmacol 1994;112:487-492.

41. Hilderman RH, Casey TE, Pojoga LH. $\mathrm{P}^{1}, \mathrm{P}^{4}$-Diadenosine 5-tetraphosphate modulates $\mathrm{L}$-arginine and I-citrulline uptake by bovine aortic endothelial cells. Arch Biochem Biophys 2000;375:124-130.

42. Wu G, Meininger Cl. Regulation of L-arginine synthesis from L-citrulline by Lglutamine in endothelial cells. Am J Physiol Heart Circ Physiol 1993;265:H1965-H1971.

43. Herskowitz K, Bode BP, Block ER, Souba WB. Characterization of L-glutamine transport by pulmonary artery endothelial cells. Am J Physiol Lung Cell Mol Physiol 1991;260: L241-L246.

44. Pan M, Wasa M, Ryan U, Souba W. Inhibition of pulmonary microvascular endothelial glutamine transport by glucocorticoids and endotoxin. JPEN J Parenter Enteral Nutr 1995; 19:477-481.

45. Steiger V, Deneke SM, Fanburg BL. Characterization of glutamic acid uptake by bovine pulmonary arterial cells. J Appl Physiol 1987;63:1961-1965.

46. Sharma S, Kumar S, Sud N, Wiseman DA, Tian J, Rehmani I et al. Alterations in lung arginine metabolism in lambs with pulmonary hypertension associated with increased pulmonary blood flow. Vascul Pharmacol 2009;51:359-364. 